\title{
GIAMBATTISTA VICO EN EL TEPOZTECO
}

\author{
Jorge Velázquez Delgado \\ (Universidad Autónoma Metropolitana-Iztapalapa)
}

RESUMEN: El Autor relata su experiencia con el "Seminario Internacional" viquiano celebrado en octubre de 2007 en Tepotzotlán (México), a las faldas del volcán Tepozteco.

Palabras Clave: Vico, $350^{\circ}$ Aniversario, Tepotzotlán, Tepozteco, Mundo Moderno, J. Velázquez.

\section{Giambattista Vico in the Tepozteco}

ABSTRACT: The Author recounts his experience with the vichian "Seminario Internacional" held in October 2007 in Tepotzotlán (México), on the slope of the Tepozteco volcano.

Keywords: Vico, 350 ${ }^{\text {th }}$ Anniversary, Tepotzotlán, Tepozteco, Modern World, J. Velázquez.

Giambattista Vico nel Tepozteco

RiASSUNTO: L'Autore intende qui ripercorrere la propria esperienza acquisita nell'ambito del "Seminario internacional” vichiano tenutosi nell'ottobre del 2007 a Tepotzotlán (Messico), ai piedi del vulcano Tepozteco.

Parole ChiAve: Vico, $350^{\circ}$ Anniversario, Tepotzotlán, Tepozteco, mondo moderno, J. Velázquez.

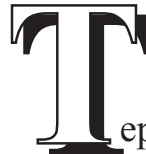

epotzotlán es uno de los atractivos turísticos más seductores y visitados por miles de turistas que se concentran en especial los fines de semana en tan místico y mítico lugar de origen prehispánico. Una de las grandes ventajas que ofrece tanto al turismo nacional y extranjero, pero sobre todo a los habitantes de la Ciudad de México, es su cercanía, pues se localiza relativamente a pocos kilómetros de dicha ciudad. La magia de Tepoztlán ha atraído a miles de personas desde aquellos tiempos, en particular por haber sido un importante centro ceremonial prehispáni-

Esta Nota responde a una invitación expresa por parte de la Dirección de la Revista para este volumen especial por el $350^{\circ}$ Aniversario del nacimiento de G. Vico. 
co. Se dice que ahí nació Quetzalcóatl, dios de los aztecas que quiere decir Serpiente Emplumada. Cuenta también con un Exconvento que durante la Colonia fue un monasterio dominicano del siglo XVI. Desde hace varias generaciones se instala un tianguis (mercado) que se caracteriza por la venta de productos artesanales. Y tiene un importante museo llamado Carlos Pellicer. Ahí se exhiben importantes muestras de la cultura prehispánica de la región. La ciudad de Cuernavaca se encuentra a pocos kilómetros de este mítico lugar y en el estado de Morelos se pueden apreciar impresionantes "paisajes zapatistas". Por último y en remembranza este lugar se aprecia también por llevarse a cabo ahí desde tiempos inmemoriales borracheras que recuerdan a los dioses antiguos. Poco recomendadas a turistas extranjeros que pueden terminar como aquel personaje de la que es quizá la más importante novela de Malcolm Lowry, me refiero a Bajo el volcán.

Fue en este impresionante lugar, justo en las faldas del Tepozteco, que durante los días 29, 30 y 31 de octubre de 2007 se llevó a cabo el Segundo Seminario Internacional: Giambattista Vico y el Mundo Moderno. ${ }^{1}$ El seminario contó con la participación de importantes personalidades académicas que se han dedicado al estudio y difusión de la obra de este insuperable filósofo napolitano. Pero también con profesores y estudiantes mexicanos interesados en conocer y estudiar la obra de este pensador. De esta forma se mantuvo durante esos días un agradable ambiente de discusión fraterna. Se tuvieron fuertes razones para realizar en ese lugar dicho Seminario. La más importante fue quizá que los profesores extranjeros pudieran llevarse la imagen de lo que es tal vez para muchos un aspecto particular de la cultura popular mexicana referida a la celebración del Día de Muertos. Que conocieran los altares y ofrendas de la más importante fiesta mexicana de origen prehispánico y que, con la llegada de los españoles, se fusiona para generar una de las más valiosas expresiones del barroquismo mexicano de profunda raíz popular. Esta fiesta no es lo que Hollywood transmite a través de una pésima película de James Bond.

La otra razón es más simple. Pues, como se sabe, con la globalización las actividades académicas se han intensificado como nunca, pero el resultado es que, a pesar de los esfuerzos realizados por organizadores y anfitriones, se muestra muy poco interés por dichas actividades. Por ello se prefirió realizar una "encerrona" para intercambiar nuestras respectivas lecturas sobre la obra de Giambattista Vico.

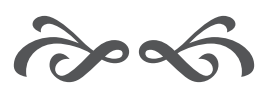

1. Las memorias de este Seminario han sido publicadas por el Departamento de Filosofía de la Universidad Autónoma Metropolitana, México, 2014. 